\section{Laparoscopic-assisted percutaneous endoscopic gastrostomy - rendez-vous PEG - in infants, children and adolescents}
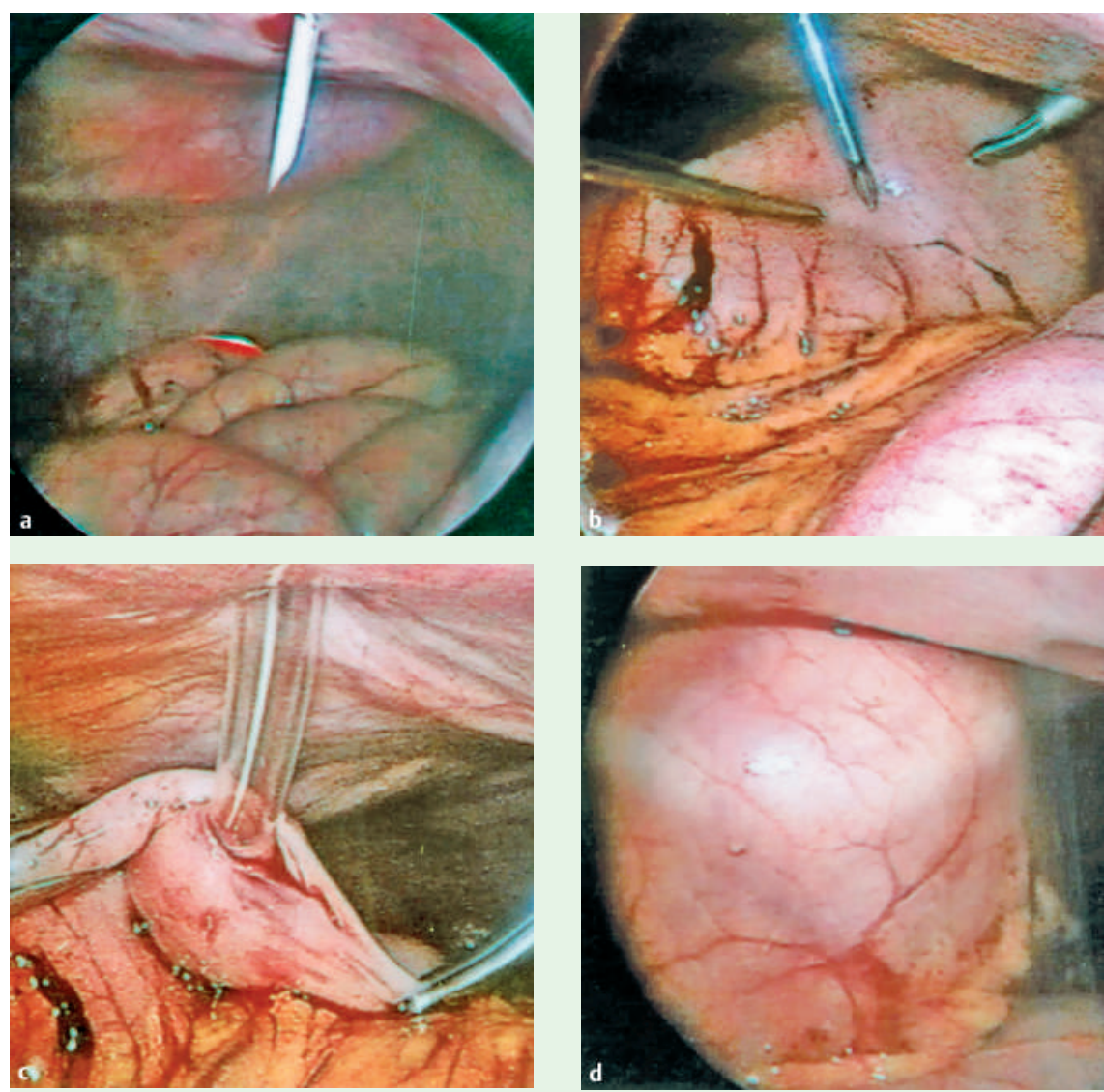

Figure 1 Laparoscopic view showing: a the transluminated stomach and the percutaneous endoscopic gastrostomy puncture cannula in the abdominal cavity; $\mathbf{b}$ the laparoscopic-assisted positioning of the stomach and its puncture by the puncture cannula; $\mathbf{c}$ the stomach being pulled to the abdominal wall from outside after insertion of the feeding tube; $\mathbf{d}$ complete apposition of the stomach to abdominal wall.

In children with insufficient oral intake, the percutaneous endoscopic gastrostomy (PEG) has become the preferred method for enteral feeding $[1,2]$. However, percutaneous puncture of the stomach may not be safe because of unfavorable anatomy. Major puncture-related complications, such as failed attempts, gastrocolocutaneous fistula, and massive hemorrhage, were seen in $9 \%$ of all children who underwent PEG [3]. In order to avoid these complications we use a combined laparoscopic-assisted endoscopic (rendez-vous) approach in selected patients.

In the past 5 years, 277 pediatric patients were referred to our unit for PEG. Nine patients (3.24\%) did not qualify for a sole- punctured under direct laparoscopic and endoscopic vision ( Figure 1a-d). The feeding tube (Freka $\mathrm{CH}$ 15, Fresenius $\mathrm{GmbH}$, Germany) was placed subsequently using the standard pull technique. The procedure was completed successfully in all patients. Median procedure time was 15 minutes (range 10-25 minutes). The only complication was one case of minor skin infection.

We propose the laparoscopic-assisted PEG technique, even in small children, whenever conventional PEG placement is not considered safe due to unfavorable anatomy [4]. The laparoscopic monitoring helps to avoid major complications of conventional PEG, such as puncture of the bowel or solid organs.

Endoscopy_UCTN_Code_TTT_1AO_2AK Endoscopy_UCTN_Code_TTT_1AT_2AF

\section{H. Köhler ${ }^{1}$, S. Razeghi ${ }^{1}$,} N. Spychalski ${ }^{2}$,

\section{R. Behrens ${ }^{1,3}$, R. Carbon ${ }^{2}$}

1 Kinder- und Jugendklinik, Universitätsklinikum, Erlangen, Germany

2 Abteilung f. Kinderchirurgie, Universitätsklinikum, Erlangen, Germany Zentrum für Neugeborene, Kinder und Jugendliche, Südklinikum, Nürnberg, Germany

\section{References}

1 Behrens R, Lang T, Muschweck H et al. Percutaneous endoscopic gastrostomy in children and adolescents. J Pediatr Gastroenterol Nutr 1997; 25: 487-491

2 Gauderer MWL, Ponsky JL, Izant RJ. Gastrostomy without laparoscopy - a percutaneous endoscopic technique. J Pediatr Surg 1980; 15: 872

3 Khattak IU, Kimber C, Kiely EM, Spitz L. Percutaneous endoscopic gastrostomy in paediatric practice: complications and outcome. J Pediatr Surg 1998; 33: 67-72

4 Lotan G, Broide E, Efrati Y, Klin B. Laparoscopically monitored percutaneous endoscopic gastrostomy in children. Surg Endosc 2004; 18: $1280-1282$

Bibliography

DOI 10.1055/s-2007-966108

Endoscopy 2007; 39: E136

(C) Georg Thieme Verlag KG Stuttgart · New York . ISSN 0013-726X

\section{Corresponding author}

\section{H. Köhler, MD}

Kinder- und Jugendklinik

Universitätsklinikum Erlangen

Loschgestr. 15

91054 Erlangen

Germany

Fax: +49-9131-85-33113

henrik.koehler@kinder.imed.uni-erlangen.de 